\title{
Synthesis of Various Polyimides Using Tetrahydrofuran/Methanol as Solvent
}

\author{
Kevin Gaw, Hironori Suzuki, Mitsutoshi JikeI, Masa-aki KaKimoto, ${ }^{\dagger}$ \\ and Yoshio IMAI
}

Department of Organic and Polymeric Materials, Tokyo Institute of Technology,
2-12-1 O-Okayama, Meguro-ku, Tokyo 152, Japan

(Received September 17, 1996)

KEY WORDS Methanol / Poly(amic acid) / Polyimide / Solvent / Tetrahydrofuran

The presence of residual solvent in the polyamic acid precursor films affects processing conditions in the fabrication of polyimide films due to the need to remove it from the system. The aprotic solvents typically used in the manufacture of polyamic acids, dimethylacetamide (DMAc) and $N$-methyl pyrrolidone (NMP), form molecular complexes with polyamic acid making the solvent particularly difficult to remove under ambient conditions. ${ }^{1-4}$ Echigo et al., have created a novel solvent system consisting of tetrahydrofuran (THF) and methanol for the fabrication of ODA-PMDA polyimides. ${ }^{5-7}$ They found that this solvent system can be used in the synthesis of high molecular weight polyamic acids that can later be thermally cured into polyimides. They developed this system to assist the incorporation of water into the solution mixture which upon curing introduces porosity into the films. This solvent system results in the easy removal of nearly all solvent from the polyamic acid prior to thermal cure. The synthesis of other polyimides using this easy to remove solvent system has heretofore not been attempted. Here is reported the synthesis of a variety of polyimides using the $\mathrm{THF} / \mathrm{MeOH}$ solvent system.

\section{GENERAL EXPERIMENTAL PROCEDURE}

Polyamic acids, as $3-12 \mathrm{wt} \%$ solutions were prepared by reacting stoichiometric amounts of diamines and pyromellitic dianhydrides for $2-12$ hours. In a three necked flask under a nitrogen purge, the diamine was first dissolved in $40-100 \mathrm{~mL}$ solvent, a $80 / 20 \mathrm{wt} \%$ mixture of THF and methanol, by mechanical stirring. Upon complete dissolution of the diamine, addition of the dianhydride as one batch resulted in a curdlike mixture. Continued stirring resulted in complete dianhydride dissolution and homogeneous solutions. Films were then cast from these solutions and after evaporation of the solvent under ambient conditions, subjected to $125^{\circ} \mathrm{C}$ for one hour and two hours at $250^{\circ} \mathrm{C}$ to imidize the films. All diamines and dianhydrides were purified by either sublimation or recrystallization from toluene prior to use. THF and methanol were used as received. The generalized reaction scheme is shown in eq 1. Various diamines and dianhydrides are drawn in

\footnotetext{
† To whom correspondence should be addressed.
}

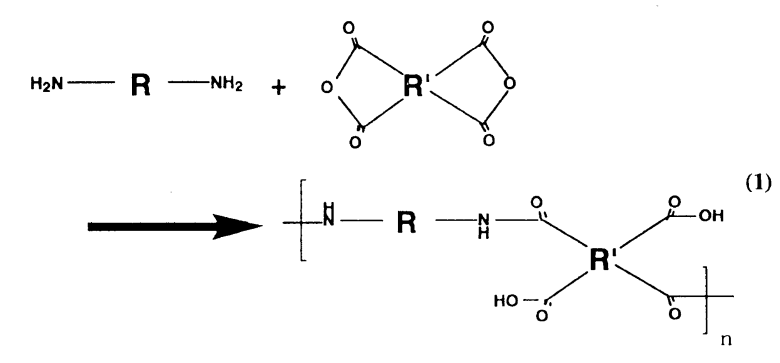

Figure 1. Viscosity measurements were conducted in concentrated sulfuric acid $\left(\mathrm{H}_{2} \mathrm{SO}_{4}\right)$ on polyamic acids precipitated from the reaction solutions by pouring the solutions into water. Ubbelohde capillary viscometry using a concentration of $0.5 \mathrm{~g} / 100 \mathrm{~mL} \mathrm{H}_{2} \mathrm{SO}_{4}$ at $30^{\circ} \mathrm{C}$ was conducted for all polyamic acids.

\section{RESULTS AND DISCUSSION}

During the synthesis of the poly(amic acid)s very unusual solution behavior was noted. Upon the addition of the dianhydride, all solutions took on a cottage cheese-like texture. However, with continued stirring for various times, $2-12$ hours, this texture disappeared and clear solutions of various colors resulted. This was accompanied by increase in the molecular weight as seen by the increase in the viscosity of the solution. The solution composition that results in the highest molecular weight of the ODA-PMDA poly(amic acid), as seen in Figure 2, is the THF/MeOH $80 / 20 \mathrm{wt} \%(78 / 22 \mathrm{vol} \%)$ solution. Figure 2 also shows the lack of solubility of the reactant in the solutions with less than $50 \mathrm{wt} \%$ and more than $90 \mathrm{wt} \%$ THF. Consequently, all further polyamic acid synthesis was conducted using the $80 / 20$ solution composition. Molecular weights of the various polyamic acids were determined from the inherent viscosity of the poly(amic acid) solutions. The inherent viscosities and solution appearance of the various poly(amic acid)s are listed in Table I. As can be seen by the relatively high inherent viscosities, the facile synthesis of the various polyimides of high molecular weight in the $\mathrm{THF} / \mathrm{MeOH}$ solvent system was achieved.

Various diamines had varying solubilities in the $80 / 20$ (THF/MeOH) solvent system. 3,3'-ODA had the lowest solubility (less than $3 \mathrm{wt} \%$ ) with 6-FDA having the highest (greater then $8 \mathrm{wt} \%$ ). The diamine must first be dissolved into the solvent because it is much less soluble than the dianhydrides and would not dissolve 

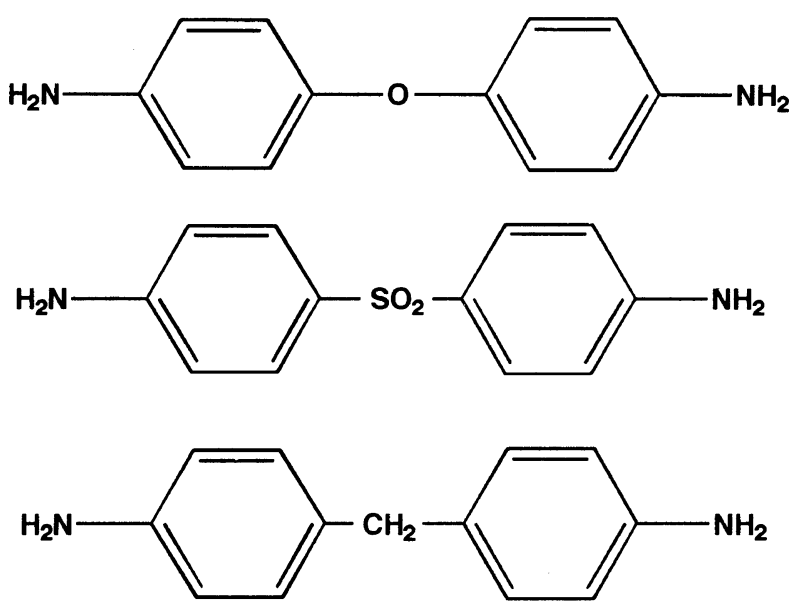<smiles>Nc1cccc(Oc2cccc(N)c2)c1</smiles><smiles>Nc1ccc(C(c2ccc(N)cc2)(C(F)(F)F)C(F)(F)F)cc1</smiles><smiles>O=c1oc(=O)c2cc3c(=O)oc(=O)c3cc12</smiles><smiles>O=C1OC(=O)c2cc(C3=CC4C(=O)OC(=O)C4C=C3)ccc21</smiles>

Oxydianilline (ODA)

Diaminodiphenylether (DDE)

Diaminodiphenylsulfone (DDS)

Diaminodiphenylmethane (DDM)

$3,3^{\prime}$ ODA

6-Fluorodianiline (6FDA)

Pyromellitic Dianhydride (PMDA)

Biphenyl Dianhydride (BPDA)

Figure 1. Structures and abbreviations of diamines and dianhydrides.

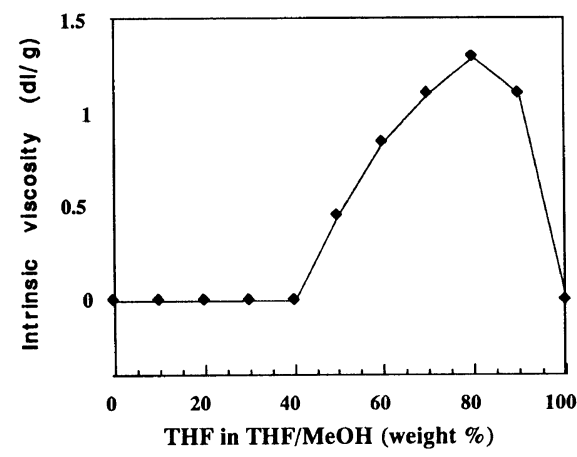

Figure 2. Inherent viscosity of ODA-PMDA polyamic acid versus THF content in THF/MeOH solution.
Table I. Reaction conditions and solution and polyamic acid precipitate appearance for various reactants

\begin{tabular}{lccrl}
\hline Diamine & Dianhydride & $\begin{array}{c}\text { Reaction } \\
\text { time/h }\end{array}$ & $\begin{array}{r}\text { Inherent } \\
\text { viscosity/ } \\
\mathrm{dLg}^{-1}\end{array}$ & $\begin{array}{c}\text { Solution/ppt. } \\
\text { color }\end{array}$ \\
\hline DDE & PMDA & 6 & 1.41 & Yellow/Yellow \\
DDM & PMDA & 3 & 0.99 & Gold/Golden \\
DDS & PMDA & 6 & 1.10 & Tan/Pale yellow \\
3,3'-ODA & PMDA & 2 & 0.89 & Gold/Yellow \\
6-FDA & PMDA & 12 & 2.42 & Clear/White \\
DDE & BPDA & 6 & 0.94 & Yellow/Yellow \\
DDS & BPDA & 6 & 0.87 & Pale brown/Tan \\
6-FDA & BPDA & 3 & 1.46 & Clear/White \\
\hline
\end{tabular}


in a solution containing dissolved dianhydride. The polymerization reaction could not be made to go forward in experiments wherein the order of addition of the components to the solution was dianhydride, diamine.

\section{CONCLUSIONS}

The use of $\mathrm{THF} / \mathrm{MeOH}$ solutions for the synthesis of polyimides is feasible and makes it possible to obtain polyamic species of high molecular weight. The $80 / 20$ $\mathrm{wt} \% \mathrm{THF} / \mathrm{MeOH}$ solutions resulted in the production of high molecular weight polyamic acids. The polyimides formed from polyamic acids seemed identical to those obtained with more conventional aprotic solvents such as dimethylacetamide (DMAc) and $N$-methylpyrrolidone
(NMP).

\section{REFERENCES}

I. J. A. Kreuz, A. L. Endrey, F. P. Gay, and C. E. Sroog, J. Polym Sci., $A-1,4,2607$ (1966).

2. M.-J. Brekner and C. Feger, J. Polym. Sci., A, Polym. Chem. Ed., 25, 2005 (1987).

3. M.-J. Brekner and C. Feger, J. Polym. Sci., A, Polym. Chem. Ed., 25, 2497 (1987).

4. M.-J. Brekner and C. Feger, J. Polym. Sci., A, Polym. Chem. Ed., 25, 2497 (1987)

5. Y. Echigo, Y. Iwaya, I. Tomioka, M. Furukawa, and S. Okamoto, Macromolecules, 28, 3000 (1995).

6. Y. Echigo, Y. Iwaya, I. Tomioka, and H. Yamada, Macrolomecules, 28, 4861 (1995).

7. Y. Echigo, Y. Iwaya, M. Saito, and I. Tomioka, Macrolomecules, 28, 6684 (1995). 